\title{
FACTORS INFLUENCING STREET TREE HAZARD CONDITION IN RAFAELA, ARGENTINA
}

\author{
Damián César Castro $^{2} \odot$, Carlos Agustín Alesso $^{2 *} \odot$, Ariana Iaconis $^{2} \odot$, María Carolina Cerino $^{3} \odot$ \\ and Marcela Buyatti²
}

\footnotetext{
${ }^{1}$ Received on 14.06.2018 accepted for publication on 21.08.2019.

${ }^{2}$ Universidad Nacional del Litoral. Facultad de Ciencias Agrarias, Cátedra de Cultivos Intensivos, Provincia de Santa Fe, Argentina. E-mail: <dcastro@fca.unl.edu.ar>,<calesso@fca.unl.edu.ar>, <mccerino@fca.unl.edu.ar>and <mbuyatti@fca.unl.edu.ar>.

${ }^{3}$ Universidade de Sydney, Faculdade de Ciência, Austrália. E-mail: < ariana.iaconis@gmail.com>.

*Corresponding author.
}

\begin{abstract}
Understanding the factors that affect tree hazard condition is important to mitigate it. To quantify these factors for Fraxinus americana L., Morus nigra L., and Populus deltoides Marshall trees we have conducted a survey recording their hazard rating according to the TRAQ methodology. The following covariates were registered for each tree: the number of single tree defects in root collar, trunk and scaffold branches, trunk diameter at breast height (DBH), crown class, crown asymmetry, and the size of the tree pit. A multi-category logistic regression model was fitted to the data using the backward step-wise procedure. Among the factors considered, only the species, crown class, number of single defects in root collar and scaffold branches significantly affected the tree hazard condition. $P$. deltoids trees had higher values of hazard compared to F. Americana and M. nigra trees. Trees with co-dominant crowns presented a higher probability of being classified as medium and high hazardous than trees with suppressed and dominant crowns. Finally, every single defect observed on root collar and scaffold branches increased the probability of a tree being of medium or high hazardous, by about 3.00 and 1.44 times, respectively. Other factors like crown asymmetry, DBH, and the tree pit size did not have a significant effect on the score of tree hazard. Our results demonstrate that the species selection is an important tool to manage urban tree hazard under the study conditions. At the species level, efforts should be directed towards minimizing defects in root collar, trunk and scaffold branches.
\end{abstract}

Keywords: Tree defects; Failure potential; TRAQ methodology

\section{FATORES QUE INFLUENCIAM NO RISCO DE QUEDA DAS ARVORES URBANAS EM RAFAELA, ARGENTINA}

\begin{abstract}
RESUMO - A compreensão dos fatores que afetam o risco de queda de árvores inteiras o suas partes (galhos estruturais e caule) é importante para amenizar tais problemas. Para quantificar esses fatores realizou-se uma análise do risco de Fraxinus americana L., Morus nigra L. e Populus deltoides Marshall por meio da metodologia TRAQ. Além disso, registraram-se as seguintes variáveis: número de defeitos no coleto, tronco e galhos estruturais, diâmetro do caule à altura do peito (DAP), classe de copa, assimetria da copa, espaço de crescimento da árvore e a espécie. Ajustou-se um modelo de regressão logística multi-categoria usando o procedimento backward stepwise. Os fatores que influenciaram significativamente o risco de queda das árvores avaliadas foram: espécie, classe de copa, o número de defeitos no coleto e nos galhos estruturais. As árvores de P. deltoides tiveram valores de risco maiores em comparação às árvores de $\boldsymbol{F}$. americana e M. nigra. As árvores de copas codominantes tiveram maior probabilidade de ser classificada como de risco médio ou alto do que as árvores de copas dominantes e intermediarias. Por último, cada defeito observado no coleto aumentou em três vezes a probabilidade das árvores de ser classificadas como de risco médio ou alto. No entanto, essas probabilidades aumentaram em 1,44 vezes por cada defeito observado nos galhos estruturais. Porém, outros fatores como DAP, assimetria da copa e o espaço de crescimento não mostraram relação com o grau de risco. Por tanto, os dados demostraram que a seleção de espécies adequadas é a ferramenta mais importante para diminuir o risco de queda das árvores urbanas e que, para cada espécie, os esforços devem ser orientados à minimização dos defeitos no coleto, tronco e galhos principais.
\end{abstract}

Palavras-Chave: Defeitos nas árvores, Potencial de falha, Metodologia TRAQ

Silf $(c)$ EY

Revista Árvore 2019;43(4):e430410 http://dx.doi.org/10.1590/1806-90882019000400010 


\section{INTRODUCTION}

Urban forests provide various ecosystem services to urban areas. Through proper design and management, urban forests can mitigate many of the environmental impacts of urban development by moderating climate, reducing building energyuse and atmospheric carbon dioxide, improving air quality and reducing noise levels. Also, functional urban forests provide habitat for wildlife and improve the architectonic and landscape value of a given city (Nowak and Dwyer, 2007)

However, inappropriate tree selection and maintenance can increase the negative impacts of urban forests on the environment, population, infrastructure and the ownership of citizens. Such negative impacts are related to pollen production and chemical emissions from trees, an increase in building energy use, infrastructure repair, sidewalks breakdown, luminaires obstruction, a hindrance to vehicular and human transit and visual discomfort (Randrup et al., 2001; Smiley et al., 2007).

Other negative impacts are related to the increase of tree hazard condition due to the aging of the urban forest, which can be accelerated due to an inadequate species selection or unsuitable forest management. A hazardous tree is characterized by structural defects or disorders that predispose it to failures, e.g.; the tree has the potential to cause harm to people or property (Ellison, 2005). Besides, a structurally sound tree may be also considered hazardous if it interferes with people's routine activities, e.g. stems or branches interfering motorist's vision, roots raising sidewalks, branches interrupting power lines and telephone wires (Smiley et al., 2007). On the other hand, risky trees are those hazardous trees that are likely to produce injury because the targets (people, vehicles, and infrastructure) have some degree of exposure to it, ranging from infrequent to high (Ellison, 2005). Hence, a hazardous tree may have a lower risk if there is not any target nearby or high if there are one or more targets below its crown or within its fall area, defined by its height.

Factors that affect tree hazard condition are related to tree species, age, defects-disorders, crown structure, sensitivity to pests and diseases, growing space and forest management practices (Koeser et al., 2017; Smiley et al., 2007; Terho and Hallaksela, 2005). Although some research has been carried out addressing species-specific differences of tree hazard in urban forests (Terho and Hallaksela, 2005) in South America and particularly in Argentina, a lack of local research on urban forest tree hazard condition is observed.

The objective of this work was to quantify the factors influencing street tree hazard condition of Fraxinus americana L., Morus nigra L., and Populus deltoides Marshall in Rafaela (Argentina). We hypothesized that street tree hazard condition is influenced by tree species, defects in root collar, trunk and scaffold branches, tree gird and diameter at breast height (DBH).

\section{MATERIAL AND METHODS}

An urban forest survey was carried out in a representative neighborhood of the city of Rafaela (Santa Fe, Argentina). The corresponding climatic type of Rafaela according to the Köppen classification is Cfa (humid temperate without dry season with very hot summers) (García et al., 2013).

The survey originally included a total of 1200 trees, being mostly street trees. Only 677 trees from the most representative species of the entire city, according to the forestry staff from the local Municipality, were selected for this study. These species in order of importance were: Fraxinus americana L., Morus nigra L. and Populus deltoides Marshall ( $\mathrm{N}=677$ trees). Visual observations of tree hazard condition were made during the winter of 2011 according to tree hazard recognition methodology of the International Society of Arboriculture (TRAQ methodology) and guidelines reported by Smiley et al. (2007).

According to this methodology, tree risk condition results from the sum of three components: (1) the potential of breakage, (2) the size of the compromised part of the tree, and (3) the target that could be hit by the part. Each component scores ranged from 1 to 4 , thus giving a final risk score ranging from 3 (minimum) to 12 (maximum). Note that components (1) and (2) are related to tree hazard; by adding the component (3), the hazard score is transformed into a risk condition. That is, by adding the component (3) the equation introduces a qualitative estimate of the probability that the population or the property would be affected by a hazardous tree.

Revista Árvore 2019;43(4):e430410 
In our study, we discarded the component (3) of the equation proposed by TRAQ methodology as we focused on the factors that affect tree hazard condition (and not risk condition). Thus, the resulting hazard score ranged from 2 to 8 .

Due to the sparsely of data, the response variable was reclassified collapsing the hazard scores into three categories: low (scores less than 4), medium (scores between 4 and 6) and high hazard (scores greater than 6) using grouping criteria similar to Jim and Zhang (2013). Jim and Zang (2013) divided the total range of tree risk in three groups of equal risk size; as risk scale is ordinal lower scores indicate low risk and high scores indicate high-risk rates. Although they worked on risk rate (and not hazard rate), the rationale is the same since our tree hazard scale is also ordinal.

Along with the visual assessment of tree hazard, the following covariates were recorded for each tree to relate them with the hazard categories:

a. Tree species (F. americana, M. nigra and $P$. deltoides),

b. Number of single tree defects in root-flare, trunk and scaffold branches; this variable indicates the presence of a single defect. For example, a number of 4 single defects indicate the presence of 4 different types of defects, not the presence of four given defects,

c. Trunk diameter at breast height (DBH),

d. Crown class; suppressed trees were whose crowns developed below the general level of the canopy, intermediate trees were those that occupied a subordinated position in the canopy, co-dominant trees were those whose crowns make up the general level of the canopy and dominant trees were those whose crowns extend above the general level of the canopy,

e. Crown asymmetry: none (the crown radius is balanced in the four cardinal positions), slight (the magnitude of the radius of the crown in a cardinal position is $50 \%$ to $75 \%$ compared to the other cardinal positions) and strong (the magnitude of the radius of the crown in a cardinal position is $0 \%$ to $50 \%$ compared to the other cardinal positions),

f. Size of the tree pit: small ( $<1$ square meter), medium (1-2 square meters), large ( $>2$ square meters).
Raw data were tabulated and summarized using bar graphs. A multi-category logistic regression model was fitted to the data via neural networks using the multinom function of the package nnet (Venables and Ripley, 2002) of R (R Development Core Team, 2017). The natural ordering of the response suggested the proportional odds logistic regression approach. However, due to the proportionality of the linear predictors was not warranted, which is a key assumption of this modeling approach, we opted for the multinomial regression approach using the low hazard category as the baseline (Agresti, 2018).

The modeling strategy consisted of fitting an initial full model including all variables. No interactions were included because the data dispersion resulted in interactions with perfect classification or were not estimable. Then the stepwise model selection procedure was applied in backward direction using the Akaike's information criterion (AIC) reduction as a criterion for model selection. The significance of each factor was assessed through Type III tests of the Analysis of Deviance using Anova function from car package (Fox and Weisberg, 2011). Finally, the effects were interpreted using the estimated odds and Tukey's pairwise test on predicted probabilities obtained through the emmeans function from emmeans package (Fox and Weisberg, 2011). A comprehensive assessment of model quality was performed computing the overall accuracy and error classification based on the confusion matrix. To test if the model improved the classification of trees into the three hazard categories, a goodness of fit chisquared test was used using a uniform distribution as a reference.

Table 1 - Type III tests of the Analysis of Deviance of the final model for level of tree hazard condition. $\mathrm{LR}=$ likelihood ratio; $\mathrm{Df}=$ degrees of freedom; $\operatorname{Pr}\left(>X^{2}\right)=p$ value. Higher values of likelihood ratio for a given covariate indicate more relevance for the model.

Tabela 1 - Testes tipo III da Análise de Desvio do modelo final para a classe de risco da árvore. $L R=$ razão de verossimilhança; $D f=$ graus de libertade; $\operatorname{Pr}\left(>X^{2}\right)=$ valor $p$. Valores altos da razão de verossimilhança para uma co-variável indica maior relevância do modelo ajustado.

\begin{tabular}{lccc}
\hline Factor & LR & Df & $\operatorname{Pr}(>\mathrm{X} 2)$ \\
\hline Species & 38.31 & 4 & $<0.0001$ \\
\hline Crown class & 27.65 & 4 & $<0.0001$ \\
\hline $\begin{array}{l}\text { Number of single } \\
\text { defects in root collar }\end{array}$ & 13.77 & 2 & 0.0010 \\
\hline $\begin{array}{l}\text { Number of single defects } \\
\text { in scaffold branches }\end{array}$ & 7.32 & 2 & 0.0258 \\
\hline
\end{tabular}

Revista Árvore 2019;43(4):e430410 


\section{RESULTS}

About $5 \%$ of the total of trees evaluated was rated with the minimum value of hazard (2). The remaining trees had hazard values distributed from 3 to 8 with the mean values around 5-6.

Cross-tabulation of hazard values by species resulted in empty cells due to $P$. deltoides was not represented in lower categories of hazard. Hazard values were reclassified into three classes: low (2 to 4), medium (5 and 6) and high (7 and 8) hazard.

According to with the Type III tests of the Analysis of Deviance, only species, crown class, number of single defects in root collar and in scaffold branches had a significant effect on the probabilities of a street tree to be classified into the low, medium or high hazard category (Table 1). The larger reduction of residual deviance was attributed to the effect of the species followed by crown class. The number of single defects in root collar and scaffold branches had significant but less important effect than species and crown class in residual deviance reductions.

The overall accuracy of the fitted model showed that it could successfully predict the tree hazard category about $56 \%$ of the times, which is statistically higher than the obtained by random $(\mathrm{X} 2=107.8, \mathrm{p}<$ $0.0001)$. However, the accuracy was variable within each hazard categories. The highest error rate was obtained for low hazard category with $62 \%$ of trees being misclassified. The inaccuracy for medium and high hazard categories was about $42 \%$ and $47 \%$.
The estimated probabilities of belonging to each tree hazard category and their $95 \%$ CI for the levels of categorical predictors are summarized in Table 2. For quantitative variables (i.e. number of single defects in root collar branches), the estimated coefficient of the model and their 95\% confidence intervals showed in Table 3 are interpreted as the effect of each additional defects on the odds of a tree of belonging to the medium and high hazard category, regarding low hazard as baseline.

The species affected the probabilities of belonging to the low or high tree hazard categories. P. deltoides individuals had significantly lower probabilities of belonging to the low hazard category compared to $F$. americana and $M$. nigra. The opposite was observed in the high hazard category; the estimated odds for $P$. deltoides trees of belonging to this category were roughly 2 times bigger than those estimated for $F$. americana and $M$. nigra trees (Table 2). When looking cumulative probabilities, for $P$. deltoides the likelihood of having a medium or lower hazard score was 0.53 , whereas for $F$. americana and M. nigra the average probability was 0.75 and 0.77 respectively, reflecting the lower hazard associated with these two species.

Differences in the probabilities of belonging to medium and high tree hazard categories were also found between crown classes. Trees with codominant crowns were associated with significantly lower probabilities of belonging to medium hazard compared to suppressed and dominant crowns. The estimated average odds for suppressed and dominant

Table 2 - Estimates and 95\% CI for the probabilities of trees belonging to hazard categories according to the levels of factors included in the multinomial model (i.e. tree species, and crown class). Different letters indicate statistical significant differences at $5 \%$ of significance according to Tukey's honestly significant difference procedure.

Tabela 2 - Valores estimados e intervalos de confiança (95\%) para as probabilidades das árvores de pertencerem às categorias de risco acordo com os níveis dos fatores incluídos no modelo multinominal. Letras diferentes indicam significância estatística pelo teste de Tukey.

\begin{tabular}{|c|c|c|c|c|c|c|}
\hline \multirow{3}{*}{ Factor } & & \multicolumn{5}{|c|}{ Tree hazard category } \\
\hline & \multicolumn{2}{|c|}{ Low } & \multicolumn{2}{|c|}{ Medium } & \multicolumn{2}{|c|}{ High } \\
\hline & Est & $95 \% \mathrm{CI}$ & Est & $95 \% \mathrm{CI}$ & Est & $95 \% \mathrm{CI}$ \\
\hline \multicolumn{7}{|l|}{ Species } \\
\hline F. americana & $0.29 \mathrm{a}$ & $(0.14,0.32)$ & $0.52 \mathrm{a}$ & $(0.42,0.62)$ & $0.25 \mathrm{a}$ & $(0.18,0.33)$ \\
\hline M. nigra & $0.16 \mathrm{a}$ & $(0.09,0.24)$ & $0.62 \mathrm{a}$ & $(0.53,0.71)$ & $0.22 \mathrm{a}$ & $(0.16,0.29)$ \\
\hline P. deltoids & $0.02 \mathrm{~b}$ & $(0.00,0.05)$ & $0.51 \mathrm{a}$ & $(0.38,0.64)$ & $0.47 \mathrm{~b}$ & $(0.34,0.60)$ \\
\hline \multicolumn{7}{|l|}{ Crown class } \\
\hline Suppressed & $0.20 \mathrm{a}$ & $(0.09,0.32)$ & $0.67 \mathrm{a}$ & $(0.50,0.85)$ & $0.13 \mathrm{a}$ & $(0,0.26)$ \\
\hline Co-dominant & $0.10 \mathrm{a}$ & $(0.05,0.16)$ & $0.38 \mathrm{~b}$ & $(0.28,0.48)$ & $0.52 \mathrm{~b}$ & $(0.42,0.62)$ \\
\hline Dominant & $0.10 \mathrm{a}$ & $(0.06,0.14)$ & $0.60 \mathrm{a}$ & $(0.53,0.66)$ & $0.30 \mathrm{a}$ & $(0.24,0.36)$ \\
\hline
\end{tabular}

Revista Árvore 2019;43(4):e430410 
Table 3 - Estimated odds and $95 \%$ for CI of the coefficients associated with the number of single defects in root flare and scaffold branches.

Tabela 3 - Probabilidades estimadas e 95\% para o IC dos coeficientes associados ao número de defeitos no coleto e galhos estruturais da copa.

\begin{tabular}{lcccc}
\hline \multicolumn{5}{c}{ e galhos estruturais da copa. } \\
\hline \multicolumn{4}{c}{ Hazard category } \\
\hline $\begin{array}{l}\text { Number of } \\
\text { single defects }\end{array}$ & Est & $95 \%$ CI & est & $95 \%$ CI \\
\hline Root flare & 3.02 & $(1.27,7.22)$ & 3.72 & $(1.53,9.08)$ \\
\hline $\begin{array}{l}\text { Scaffold } \\
\text { branches }\end{array}$ & 1.44 & $(1.09,1.90)$ & 1.41 & $(1.04,1.90)$ \\
\hline
\end{tabular}

crowns were 1.2 bigger than the odds for co-dominant crowns. The opposite was observed for the high hazard category. On average, the probability of belonging to the high hazard category was about 2.5 times higher for co-dominant crowns than for the other classes. It should be noted that the $95 \%$ confidence intervals for the suppressed crown class were less precise than for the remaining classes. This is due to the smaller number of trees having suppressed crown class in the sample.

The number of single defects in root collar had a strong effect on the odds of belonging to the medium or high tree hazard category. For instance, each additional defect observed in the root collar increased the odds in approximately 3 and 3.7 times over the baseline category. The estimated effect of each additional root collar defect on the odds of high over a medium hazard was around 1.2. However, these estimations were imprecise indicating some flaw of the model to represent the effect of this factor (Table 2). Figure 1 shows the relationship between the probabilities of each hazard category as the number of defects increase, controlled by the other factors. It can be observed that as the number of root collar defects increases, the probabilities for low hazard category decreases and increases those with high hazard. Additionally, the frequency of trees without defects was about $92 \%$ on the low hazard category, whereas on medium and high hazard categories this proportion diminished up to about $81 \%$. In the remaining $19 \%$, some signs of decay were observed, being cavities the most important (Table 4).

The number of single defects in scaffold branches was the less important factor in our model. Each additional defect observed on scaffold branches increased approximately 1.4 times the probability of a

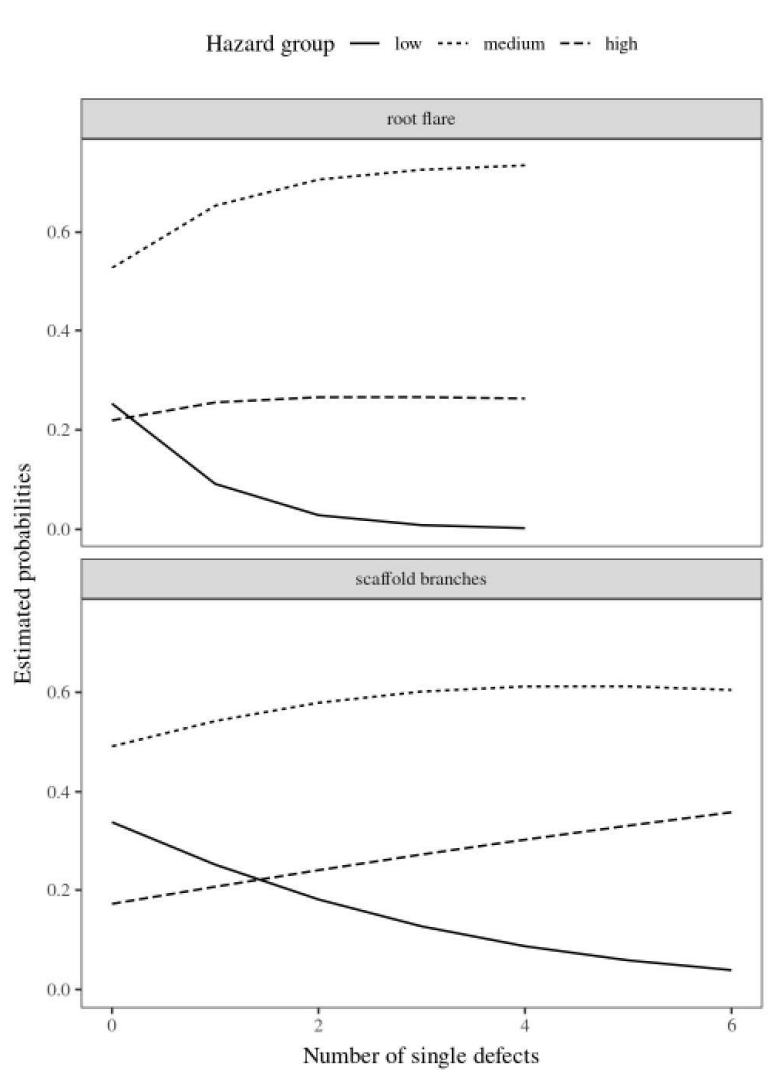

Figure 1 - Effect of number of single defects on root-flare and scaffold branches on the estimated probabilities of belonging to low (solid line), medium (dashed line) and high (dotted line) tree hazard classes.

Figura 1 - Efeito do número de defeitos no coleto e galhos estruturais sob as probabilidades estimadas de uma árvore ser classificada na categoria de risco baixa (linha solida), médio (linha tracejada) ou alto (linha pontilhada).

tree of being considered as medium or high hazardous. When regarding the medium hazard as the baseline, the estimated effect of each additional scaffold branch defect was roughly $\approx 1$ meaning that the effect was negligible. It can be observed that as the number of single defects on scaffold branches increased, the probabilities for low hazard category declined and raised those for the medium hazard (Fig. 1). The effect of the number of defects on the scaffold branches on the probabilities of the high hazard category was nearly negligible. On the other hand, the most observed single defect was the excessive-end weigh of the scaffold branches (Table 4). Furthermore, on medium and high hazard categories other defects observed were the presence of 
Table 4 - Most important defect observed on root flare, trunk and scaffold branches on low-, medium- and high hazard categories. The data is expressed as percentage of trees with a given defect. The defects presented were the most important; however other defects could be observed in the same tree. (L, M and H indicates hazard categories; Low, Medium and High).

Tabela 4 - Defeitos mais importantes observados no coleto, caule e galhos estruturais nas categorias de risco baixa, média e alta. Os dados estão em porcentagem de árvores com um defeito particular. Os defeitos apresentados foram os mais importantes, no entanto, outros defeitos poderiam ter sido observados na mesma árvore. (L, M e H indicam as categorias de risco baixo, médio e alto, respectivamente).

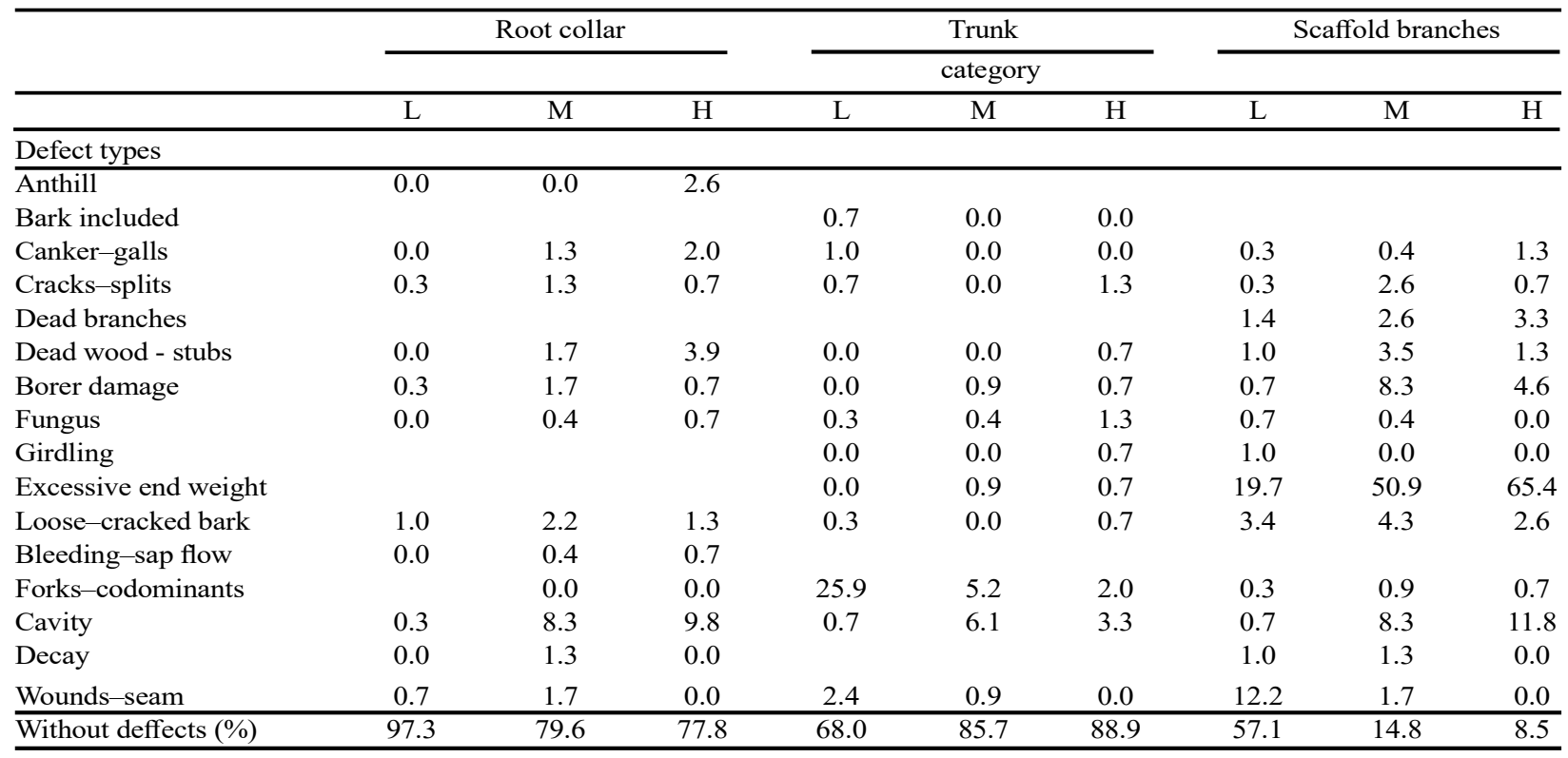

cavities and borers, but in less than $12 \%$ of the trees. The proportion of trees without defects was greater in the low hazard category (Table 4).

\section{DISCUSSION}

Results suggest that the factors that explained tree hazards under our conditions were, in order of importance; the species, crown class, number of defects in root collar and the number of defects in scaffold branches. These results led us to reject our hypothesis as trunk defects, tree pit size and diameter at breast height $(\mathrm{DBH})$ were not statistically significant in the adjusted model. The overall accuracy of the fitted model showed that it could be successfully predicted the tree hazard category in about $56 \%$ of the times. Although the accuracy of low and high hazard categories was lower (53\% and 39\% respectively) than overall accuracy, it was still higher than obtained randomly. However, our objective was to determine those factors that affect tree hazard condition of a given tree, and not to predict the hazard rate of a given tree based on its characteristics, using the model. We adjusted a model to explain and not to infer the tree hazard condition. Explain the factors that affect tree hazard condition is also useful to urban tree management.

All the factors retained by the adjusted model had a high statistical significance, but its accuracy showed some "noise" which leads us to be cautious in interpreting and explaining the observed trends, despite their high statistical significance. Many factors can affect the precision of the model, among them the methodology used to estimate tree-hazard might be the most important. We used a tree-hazard rating that was composed of two factors; 1) failure potential rating, estimating by quantifying tree defects and the likelihood of breakage interpreted based on the observer experience and 2) the size of the part most likely to fail. Although the second component of tree hazard condition is quite objective according with TRAQ methodology, the first component depends upon the observer bias (e.g: its perception of failure potential according to tree defects or disorders observed). Additional variability could stem from ambiguities or misunderstandings that could be related to the assessment method used (Koeser and Smiley,

Revista Árvore 2019;43(4):e430410 
2017). Nevertheless, our data do not allow us to quantify the portion of the model error attributed both to an observed and methodology bias. Despite this, we speculate that the lack of objectivity about failure potential in TRAQ methodology had a greater impact on the overall accuracy of the adjusted model than the observer, as we used two experimented assessors which is known to reduce the impact of observer bias (Koeser and Smiley, 2017). Another factor that may have contributed to the "noise" of the model is the great variability in genotypes within each species. $M$. nigra and $F$. americana are often propagated by seed without uniformity and selection for desirable traits for urban forests as decay compartmentalization in Argentina. $P$ deltoides is propagated by cuttings, but regardless of this, it was found that the compartmentalization capacity was clone-dependent in this genus (Shigo et al., 1977), and there is no certainty that a single clone of this species has been used in the study city.

Species was the most relevant factor for tree hazard condition in our work. Studies carried out by Terho and Hallaksela (2005b), Kane (2008) and Jim and Zhang (2013) showed that failure potential is species-dependent, which is in agreement with our results. We found that $P$. deltoides was the most hazardous species whereas $M$. nigra and F. americana were the less hazardous. Tree-hazard factors strictly related to species are crown architecture, wood decay resistance and compartmentalization capacity (Shortle, 1979). In this regard, there are marked differences on decay resistance between such species and genotypes within species (Shigo et al., 1977). According with the literature, the most tolerant to decay is Morus sp., while F. americana and $P$. deltoides are the less resistant (Loehle, 1988; Scheffer and Morrell, 1998), which may be related to poor compartmentalization capacity. In species of fast growth and low longevity like Pupulus sp., decay resistance and compartmentalization capacity weaken with age, thus aged trees are more prompted to decay than young fast-growing trees (Loehle, 1988). On the other hand, inappropriate pruning methods like topping are often utilized in the study area which is known to contribute to forming a decay column into branches pruned (Gilman and Knox, 2005). The response of trees to such interventions will depend on their wood decay compartmentalization capacity, which is related to genotype.
The crown class was the second factor that contributed to the model. The major differences were observed between co-dominant, versus suppressed and dominant crowns in medium and high tree hazard category (Table 2). We speculate that trees with codominant crowns would be more likely to have had a history related to poor pruning operations and windstorm damages that raised their probability of being classified as high hazardous in comparison with the other crown categories. That is, improper pruning practice will impact more on those trees with codominant crowns because they were more abundant than the other categories. Crown class affects tree hazard because failure potential due uproot and trunk failure was reported as higher on larger trees (such as those with large and dense crowns) under windstorm events (Kane, 2008), however, this relationship is not always true (Jim and Liu, 1997). Nevertheless, it should be noted that the precision of the effect of suppressed and co-dominant crown class on medium and high hazard categories in our study was low, which could originate trends that are not biologically clear.

The number of defects in the root collar rose the probability of a tree being considered as medium hazardous and decreased the probability of being considered as low hazardous (Table 3, Fig. 1). About $14 \%$ and $18 \%$ of the trees included in medium and high hazard categories had signs of decay, being the presence of cavities the most important (Table 4). In these hazard categories, the absence of defects was observed in about $80 \%$ of the trees (Table 4 ). On the other hand, there was no defect observed on $97 \%$ of low hazardous trees (Table 4). Cavities represent a deterioration of bark, sapwood, and heartwood and they are usually located where the initial injury, which started the decay process, occurred (Smiley et al., 2007). In Tilia sp. and Acer sp., about $25 \%$ of the studied trees that were knocked down for being considered hazardous, had symptoms of decay, such as hollows or decayed wood near the root collar (Terho and Hallaksela, 2008). Decay in the root collar raises the failure potential because a high proportion of its cross-sectional area could be deteriorated by fungus or dead wood. Thus, our results support previous findings by Terho and Hallaksela (2008). However, Kane (2008) found that most of Pinus sp. trees uprooted $(82 \%)$ had no visible defects, without girdling roots or obstructions to root growth. 
The number of defects in scaffold branches had a significant effect on tree hazard condition (Table 1). On high hazard trees, the most important defect observed was an excessive end weight of scaffold branches (observed on the $65 \%$ of the cases. Table 4). Excessive end weight or low live crown ratio are often caused by poor pruning practices and can lead to branch failures (Smiley et al., 2007). Heavy scaffold branches decrease tree stability under windstorms, raising its failure potential, which is aggravated when such scaffolds have leaves. The amount of weight removed by pruning was linearly related to a reduction in wind load on Acer rubrum, compared to the same trees before pruning (Smiley and Kane, 2006). Furthermore, the presence of heavy scaffold branches must be avoided, because branch attachment loses strength when branch diameter approximates to trunk diameter (Gilman, 2003). Previous reports probed that an experimented tree risk assessor can overestimate the failure potential of branches in comparison to trunk or root failures (Koeser and Smiley, 2017) because of its greater visibility. However, in our study, the high frequency of defects in the crown could be due to poor pruning operations often made by unqualified workers, which is frequent in the study area. Absent of pruning can cause poor tree architecture, unbalanced tree growth and excessive scaffold weigh. In most cities of the study area, pruning operations are made without protocols as ANSI, for example. Furthermore, workers do not have the required training in most cases, so the results are not optimal in pruning operations. On the other hand, poor pruning operations leads to an increase in the length of decayed column downward in the scaffolds (Gilman and Knox, 2005), which rises de failure potential of such scaffold branches. As discussed in the previous paragraphs the number of defects in scaffold branches is expected to be a serious problem in our study area and it is not so dependent on the risk assessor perception.

On the other hand, the size of the tree pit was not related to the tree hazard condition. Although sidewalks and paved roads can reduce the soil volume explored by roots, they can grow at shallow depths at the interface of the paving structures and the topsoil layers (Lesser, 2001). Moreover, root growth can be observed beneath cracked sidewalks because cracks favor the entry of oxygen into the soil (D'Amato et al., 2002) and presumably, water. Thus, under these conditions, the effects of tree pit size on tree hazard could be negligible, which may explain the results observed in our work.

\section{CONCLUSIONS}

Under our conditions, tree hazard condition was influenced by a mix of tree-specific factor. The effect of all site-specific factors (e.g. tree pit size), on the tree hazard, were non-significant. Among tree factors, the most important on tree hazard condition were; the species, crown class, number of defects on root flare and scaffold branches. Other tree-related factors like crown asymmetry and trunk defects were not significant. Thus, the species selection is the most important tool to manage tree hazard condition under our conditions being $F$. americana y M. nigra moderate to low hazardous species. Within species level, management efforts should be directed to minimize the defects and disorders in scaffold branches and root flare.

\section{ACKNOWLEDGEMENTS}

Damian César Castro and Carlos Agustín Alesso contributed equally.

The authors would like to thank the Municipality of Rafaela for financing the data collection and allowing using it for writing the present research paper. Data analysis and interpretation, and writing of the report were financed by the Universidad Nacional del Litoral (Argentina).

\section{REFERENCES}

Agresti A. An introduction to categorical data analysis. 3rd ed. Hoboken, NJ: Wiley-Interscience; 2018. ISBN: 978-1-119-40528-3.

D'Amato NE, Sydnor TD, Hunt R, Bishop B. Root growth beneath sidewalks near trees of four genera. Journal of Arboriculture. 2002;28(6):283-90.

Ellison MJ. Quantified tree risk assessment used in the management of amenity trees. Journal of Arboriculture. 2005;31(2):57-654.

Fox J, Weisberg S. An R Companion to Applied Regression [Internet]. 2nd ed. Thousand Oaks, CA: SAGE Publications, Inc; 2011. [cited 2017 Apr 17]. Available from: http://socserv.socsci.mcmaster.ca/ jfox/Books/Companion/ 
García MS, Leva P, Tóffoli G, Gariglio N, Valtorta V. Porciones de frio acumuladas en la region centro de la provincia de Santa Fe. Fave Sección Ciencias Agrarias. 2013;12(1-2):07-11. doi: https://doi. org/10.14409/fa.v12i1/2.5113

Gilman EF. Branch-to-stem diameter ratio affects strength of attachment. Journal of Arboriculture. 2003;29(5):291-94.

Gilman EF, Knox GW. Pruning type affects decay and structure of Crapemytle. Journal of Arboriculture. 2005;31(1):48-53.

Jim CY, Liu HHT. Storm damage on urban trees in Guangzhou, China. Landscape and Urban Planning. 1997;38(1-2):45-59. doi: https://doi.org/10.1016/ S0169-2046(97)00018-2

Jim CY, Zhang H. Defect-disorder and risk assessment of heritage trees in urban Hong Kong. Urban Forestry \& Urban Greening. 2013;12(4):58596. doi: https://doi.org/10.1016/j.ufug.2013.06.003

Kane B. Tree failure following a windstorm in Brewster, Massachusetts, USA. Urban Forestry \& Urban Greening. 2008;7(1):15-23. doi: https://doi. org/10.1016/j.ufug.2007.11.001

Koeser AK, Hauer RJ, Klein RW, Miesbauer JW. Assessment of likelihood of failure using limited visual, basic, and advanced assessment techniques. Urban Forestry \& Urban Greening. 2017;24:71-9. doi: https://doi.org/10.1016/j.ufug.2017.03.024

Koeser AK, Smiley ET. Impact of assessor on tree risk assessment ratings and prescribed mitigation measures. Urban Forestry \& Urban Greening. 2017;24:109-15. doi: https://doi.org/10.1016/j. ufug.2017.03.027

Lesser LM. Hardscape damage by tree roots. Journal of Arboriculture. 2001;27(5):272-76.

Loehle C. Tree life history strategies: the role of defenses. Canadian Journal of Forest Research. 1988;18(2):209-22. doi: https://doi.org/10.1139/x88032

Nowak DJ, Dwyer JF. Understanding the Benefits and Costs of Urban Forest Ecosystems. In: Kuser JE, editor. Urban and Community Forestry in the Northeast [Internet]. Dordrecht:
Springer; 2007. [cited 2016 Oct 21]. p. 25-46. Available from: http://link.springer.com/ chapter/10.1007/978-1-4020-4289-8_2

R Development Core Team. R: A Language and Environment for Statistical Computing [Internet]. Vienna, Austria: R Foundation for Statistical Computing; 2017. Available from: http://www.Rproject.org

Randrup TB, McPherson EG, Costello LR. A review of tree root conflicts with sidewalks, curbs, and roads. Urban Ecosystems. 2001;5(3):209-25.

Scheffer TC, Morrell JJ. Natural durability of wood: a worldwide checklist of species [Internet]. Corvallis, Or.: College of Forestry, Forest Research Laboratory, Oregon State University; 1998. Available from: http://ir.library.oregonstate.edu/xmlui/ handle/1957/7736

Shigo AL, Shortle WC, Garrett PW. Notes: Genetic Control Suggested in Compartmentalization of Discolored Wood Associated with Tree Wounds [Internet]. 1977. [cited 2018 Feb 23]. Available from: http://www.ingentaconnect.com/content/saf/ fs/1977/00000023/00000002/art00008

Shortle WC. Mechanisms of Compartmentalization of decay in Living trees. Phytopathology. 1979;69(10):1147-51.

Smiley ET, Fraedrich BR, Fengler PH. Hazard Tree Inspection, Evaluation, and Management In: Kuser JE, editor. Urban and Community Forestry in the Northeast [Internet]. Netherlands: Springer; 2007. [cited 2016 Oct 21]. p. 277-294. Available from: https://link.springer.com/ chapter/10.1007/978-1-4020-4289-8_17

Smiley ET, Kane BC. The effects of pruning type on wind loading of Acer rubrum. Arboriculture \& Urban Forestry. 2006;32(1):33-40.

Terho M, Hallaksela A-M. Potential hazard characteristics of Tilia, Betula, and Acer trees removed in the Helsinki City Area during 2001-2003. Urban Forestry \& Urban Greening. 2005;3(2):113-20.

Terho M, Hallaksela A-M. Decay characteristics of hazardous Tilia, Betula, and Acer trees felled by municipal urban tree managers in the Helsinki City 
Area. Forestry. 2008;81(2):151-59. doi: https://doi. org/10.1093/forestry/cpn002

Venables WN, Ripley BD. Modern Applied
Statistics with S [Internet]. 4th ed. New York, USA: Springer New York; 2002. [cited 2017 Apr 17]. Available from: http://link.springer.com/ chapter/10.1007/978-0-387-21706-2_12 